\title{
Economics and Cost-Effectiveness of Multiple Sclerosis Therapies in the USA
}

\author{
Daniel M. Hartung ${ }^{1}$
}

Published online: 15 August 2017

(C) The American Society for Experimental NeuroTherapeutics, Inc. 2017

\begin{abstract}
Multiple sclerosis (MS) is a disabling, chronic disease that imposes a significant economic burden on patients and the US healthcare system. The largest cost component for individuals with MS are prescription drugs, specifically disease-modifying therapies (DMTs). Despite an increase in the number and diversity of DMTs over the past 10 years, acquisition costs for all DMTs have escalated dramatically at rates substantially higher than medical inflation. Currently, costs for most DMTs exceed $\$ 70,000$ a year. Recent cost-effectiveness studies suggest the cost for nearly all DMTs exceeds generally accepted thresholds for what is considered a good value in the USA, even after factoring expected rebates. The high cost of DMTs is symptomatic of systemic dysfunction in the pharmaceutical market. Strategies aimed at reigning in high-cost medications include proposals ranging from increasing pricing transparency to allowing Medicare to negotiate directly with manufacturers. Because the economics of pharmaceuticals are inherently complex, a diversity of approaches will be required.
\end{abstract}

Keywords Healthcare economics · pharmaceuticals · multiple sclerosis $\cdot$ disease modifying therapy

Electronic supplementary material The online version of this article (doi:10.1007/s13311-017-0566-3) contains supplementary material, which is available to authorized users.

Daniel M. Hartung

hartungd@ohsu.edu

1 Oregon State University/Oregon Health and Science University College of Pharmacy, Collaborative Life Sciences Building (CLSB), 2730 SW Moody Ave., CL5CP, Portland, OR 97201-5042, USA

\section{Introduction}

Multiple sclerosis (MS) is a chronic autoimmune condition affecting the central nervous system and associated with significant premature disability [1]. The global prevalence of MS is estimated to be $>2.3$ million; $>400,000$ individuals in the USA are affected [2]. The total economic burden of MS in the USA has been estimated to be approximately $\$ 2.5$ billion and lifetime costs for individual patients exceed $\$ 4$ million [3, 4].

The peak incidence of MS occurs around 30 years of age, making it a leading cause of nontraumatic disability in young to moderately aged individuals $[5,6]$. Nearly $30 \%$ of individuals with MS in the USA are reliant on public disability insurance (i.e., Social Security Disability Insurance) [7]. MS is a disabling condition that primarily affects younger workingage individuals. Consequently, the indirect costs of lost productivity are substantial. Workers with MS have approximately 4-fold higher disability and absenteeism-related costs than employees without MS [8]. Costs due to lost productivity are over one-third of total costs for MS [9]. However, the single largest driver of MS-related healthcare expenditures are prescription drugs, which account for more than half of all direct medical costs [9]. In particular, the costs for diseasemodifying therapies (DMTs) have increased dramatically over the last 10 years $[10,11]$. Acquisition costs for nearly all DMTs presently exceed $\$ 70,000$ annually. The high costs for DMTs has a cascade of negative consequences on patients, ranging from excessive cost-sharing or deductible amounts [12] to restrictive insurance barriers, which can negatively affect care [13]. Additionally, high-cost DMTs place considerable burden on the healthcare system. The objective of this narrative review is to summarize current economic issues related to MS DMTs. Specifically, this review will highlight current pricing and reimbursement trends, describe the economics of the pharmaceutical marketplace, review recent cost- 
effectiveness studies, and outline potential strategies that respond to these issues.

\section{Drug Pricing}

The high cost of medical care for individuals with MS is fueled primarily by spending and price inflation among MS DMTs. The soaring costs of prescription drugs is largely attributable to market dysfunction that is characterized by lack of price transparency, regulatory structures that foster monopolistic conditions, uncertainty in the clinical evidence-base, and payer and supply-chain issues [14]. A comprehensive discussion of trends in pricing cannot be had without considering the broader context of the pharmaceutical market. Pharmaceutical purchasing, which involves multiple stakeholders, is one of the least transparent and convoluted transactions in healthcare $[15,16]$. Figure 1 describes the complex flow of money and drug products through pharmaceutical distribution channels. Within this framework, drug products are purchased from manufacturers by distributors who, in turn, sell and deliver product to individual pharmacies. The framework and payment arrangements are somewhat different for pharmaceuticals that are administered in a physician's office. Currently, $85 \%$ of all pharmaceutical sales are consolidated through 3 large disturbers (AmerisourceBergen, Cardinal Health, and McKesson) [16]. The flow of money is more complex. While payments for outpatient pharmaceuticals (nonclinic or hospital administered) are anchored to publically available benchmark list prices, the ultimate cost for drugs is determined by a complex web of proprietary contracts and agreements between payers, distributors, pharmacies, and

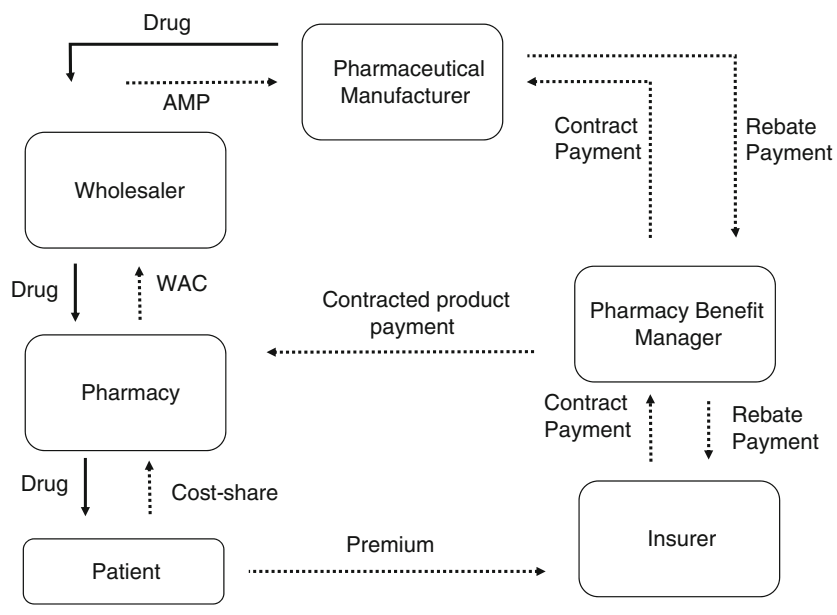

Fig. 1 Schematic of the flow of money and drug product in the drug distribution system. Sold lines represent drug product movement. Dashed lines represent payments. Figure adapted from Academy of Managed Care Pharmacy Guide to Pharmaceutical Payment Methods (2013 Update).

AMP $=$ Average Manufacturer Price; WAC $=$ Wholesale Acquisition Cost other intermediaries. The most widely used pricing benchmark for branded drugs is Wholesale Acquisition Cost (WAC), which is set by the manufacturer. WAC is defined by regulators as the list price paid to distributors without any rebates or discounts [15]. From this benchmark, discounts and rebates are applied by a variety of different stakeholders in the drug distribution channel. These relationships can vary dramatically between public [Medicaid, Medicare, Department of Veterans Affairs (VA)] and private payers, with profound consequences. For instance, the VA is commonly cited as a model to emulate because they are able to extract substantial discounts from industry. However, the VA's ability to negotiate these discounts is predicated on the organization's vertical integration and strict control of utilization. More typically, drug purchasing is mediated through pharmacy benefit managers, who negotiate discounts (reductions in price) and rebates (funds returned to payer) for most commercial and public payers (Medicare, Medicaid). Medicaid, which is financed jointly by federal and state governments, is statutorily required to receive the lowest price available to most payers (Medicaid Best Price). At a minimum, manufacturers are required to pay a $23.1 \%$ rebate off the Average Manufacture Price for branded drugs and $13.1 \%$ for generics [15]. This rebate is generally the floor and can be larger if other payers have negotiated larger concessions. Moreover, states can negotiate individual supplemental rebates. Consequently, the Medicaid program acquires considerably better prices than Medicare, which is administered through hundreds of individual Part D plans [17]. Regardless, contracted discounts and rebates are confidential and the true net costs to payers is rarely known.

\section{DMT Pricing Trends and Spending}

Figure 2 summarizes the rapid escalation in annual acquisition costs for DMTs from 1993 to 2017. As previously reported, prices for interferon (IFN) and glatiramer acetate-based platform therapies have accelerated dramatically over the past 15 years [10]. Despite the approval of a variety of novel DMTs, including the first generic - glatiramer acetate (GlatopaTM) in June 2015 - there is little evidence that pricing trends have abated. In Table 1, WAC-based annual prices, estimates of net cost to specific payers, and median annual pricing changes are reported. Prior to the approval of subcutaneous IFN- $\beta 1 \mathrm{a}$ (Rebif ${ }^{\mathrm{TM}}$ ) in 2002, annual price increases for available DMT platform therapies (IFNs or glatiramer acetate) remained $<3 \%$ per year. However, between 2002 and the approval of fingolimod, the first oral DMT, in 2010, the annual cost of IFN- $\beta 1 \mathrm{~b}$ (Betaseron $\left.{ }^{\mathrm{TM}}\right)$, IFN- $\beta 1 \mathrm{a}\left(\right.$ Avonex $\left.^{\mathrm{TM}}\right)$, and glatiramer acetate (Copaxone ${ }^{\mathrm{TM}}$ ) increased rapidly from $16 \%$ to $18 \%$ per year. Annual price inflation for these drugs has only marginally declined following the approval of fingolimod. Median annual price inflation for the 3 oral DMTs (fingolimod, 


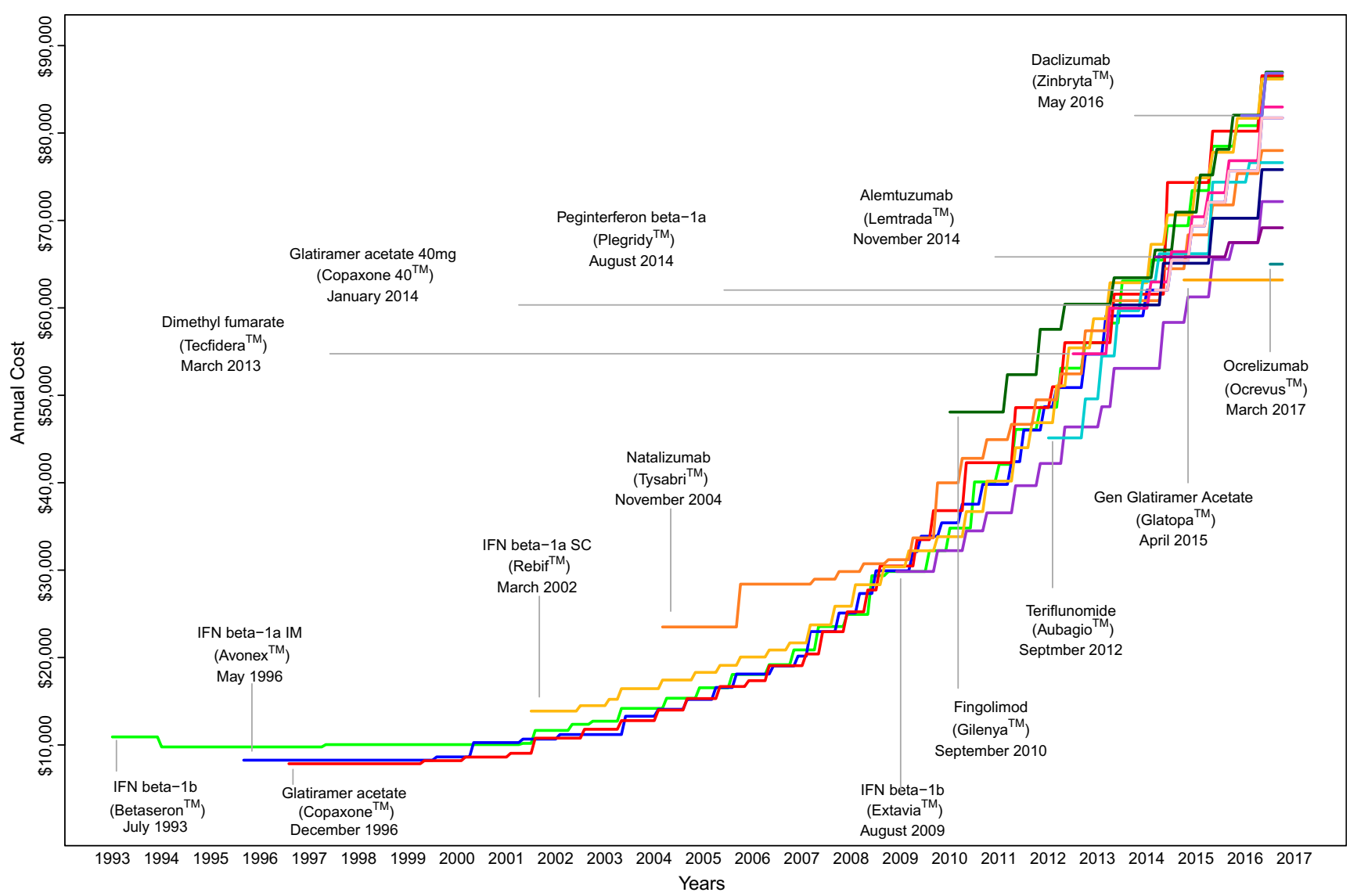

Fig. 2 Trends in disease modifying therapy (DMT) pricing. Pricing estimated from WAC for year of therapy. Alemtuzumab estimate is based on average of first- $(60 \mathrm{mg})$ and second-year dose $(36 \mathrm{mg})$

IFN = interferon; $\mathrm{SC}=$ subcutaneous

teriflunomide, dimethyl fumerate) has varied between $5 \%$ and $18 \%$ a year. Also summarized in Table 1 are estimated annual costs for state Medicaid programs and the VA. As previously mentioned, the VA is able to extract large discounts from manufacturers because of their size and ability to purchase drugs directly from manufacturers. Consequently, VA prices for DMTs are often $20 \%$ to $50 \%$ lower than list price.

There have been several important developments in the last several years. First, in January 2015, Glatopa, the first generic of glatiramer acetate $20 \mathrm{mg}$, was approved. In contrast to prevailing trends, pricing of Glatopa has remained unchanged for nearly 3 years. The much anticipated ocrelizumab (Ocrevus $^{\mathrm{TM}}$; Roche) was approved in March of 2017 with a WAC of $\$ 16,250$ per $10 \mathrm{ml}$ or $\$ 65,000$ per year, significantly lower than most other DMTs. Whether or not the pricing trajectory of ocrelizumab remains significantly below other DMT remains to be seen.

It is important to consider the net costs to payers, because most WAC-based price estimates do not include any potential rebates or discounts. Although this is challenging to estimate, a recent report produced through the Massachusetts Office of the Attorney General finds that rebates have not risen at rates large enough to compensate for price increase overall and within the specialty drug class [18]. Importantly, analysis of specific DMTs revealed that net rebate costs for 10 DMTs increased substantially from approximately $\$ 36,000$ in 2001 to $\$ 60,000$ in 2015 .

The single largest payer of MS-related costs in the USA is the Medicare program. Table 2 summarizes Medicare Part D expenditures for 12 DMTs from 2011 to 2015. Between 2011 and 2015, expenditures for DMTs more than doubled from $\$ 1.5$ billion to $\$ 4.0$ billion. In 2015, Medicare spent over $\$ 1.3$ billion on glatiramer acetate alone. In comparison, Skolarus et al. [19] reported that Medicare paid neurologists $\$ 1.15$ billion for clinical services in 2012. Rising expenditures have been driven largely by expansion in the DMT market and price increases. Among IFN and glatiramer-based platform therapies, there was very little change in the number of prescriptions or patients treated but the average cost per patient increased 68\% from \$28,975 in 2011 to $\$ 48,987$ in 2015.

\section{The Effect of High Drug Prices on Patient Care}

The ultimate consequence of high drug prices for persons with MS is reduced patient access to DMTs, which can manifest in 
Table 1 Disease modifying therapy (DMT) annual costs from market introduction to present, estimated Medicaid costs, and VA costs

\begin{tabular}{|c|c|c|c|c|c|c|c|}
\hline \multirow[t]{2}{*}{$\begin{array}{l}\text { DMT } \\
\text { (approval date) }\end{array}$} & \multirow{2}{*}{$\begin{array}{l}\text { Annual cost } \\
\text { at market } \\
\text { introduction } \\
\text { (\$) }\end{array}$} & \multicolumn{3}{|c|}{$\begin{array}{l}\text { Median annual cost } \\
\text { increases }(\%)\end{array}$} & \multirow[t]{2}{*}{$\begin{array}{l}2017 \text { annual } \\
\text { cost }(\$)^{*}\end{array}$} & \multirow{2}{*}{$\begin{array}{l}2017 \text { cost net standard } \\
\text { medicaid rebate } \\
(\$)^{\dagger}\end{array}$} & \multirow{2}{*}{$\begin{array}{l}2017 \text { big-4 } \\
\text { pricing } \\
(\$)\end{array}$} \\
\hline & & $1998-2001$ & $\begin{array}{l}2002- \\
09\end{array}$ & $2010-16$ & & & \\
\hline IFN- $\beta 1 b ;$ Betaseron $^{\mathrm{TM}}$ (July 1993) & 10,920 & 0.0 & 15.9 & 14.1 & 86,421 & 66,458 & 38,261 \\
\hline IFN-ß1a IM; Avonex ${ }^{\text {тM }}$ (May 1996) & 8261 & 2.3 & 17.6 & 16.1 & 81,731 & 62,851 & 46,452 \\
\hline $\begin{array}{l}\text { Glatiramer acetate; Copaxone }{ }^{\mathrm{TM}} 20 \mathrm{mg} \\
\text { (December 1996) }\end{array}$ & 7852 & 2.5 & 18.1 & 16.5 & 86,554 & 66,560 & 48,821 \\
\hline IFN- $\beta 1$ a SC; Rebif ${ }^{\text {TM }}($ March 2002) & 13,875 & NA & 13.7 & 12.5 & 86,179 & 66,272 & 31,409 \\
\hline Natalizumab; Tysabri ${ }^{\text {TM }}$ (November $2004 \$$ ) & 23,500 & NA & 6.1 & 11.3 & 78,000 & 59,982 & 41,299 \\
\hline IFN- $\beta 1$ b; Extavia ${ }^{\mathrm{TM}}$ (August 2009) & 29,842 & NA & NA & 13.4 & 72,160 & 55,491 & 35,006 \\
\hline Fingolimod; Gilenya ${ }^{\mathrm{TM}}$ (September 2010) & 48,083 & NA & NA & 9.5 & 86,966 & 66,877 & 48,610 \\
\hline $\begin{array}{l}\text { Teriflunomide; Aubagio } \\
\quad \text { (September 2012) }\end{array}$ & 45,124 & NA & NA & 18.3 & 76,612 & 58,915 & 48,987 \\
\hline 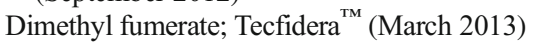 & 54,750 & NA & NA & 5.0 & 82,977 & 63,809 & 46,745 \\
\hline $\begin{array}{l}\text { Glatiramer acetate; Copaxone } 40 \mathrm{mg}^{\mathrm{TM}} \\
\quad \text { (January 2014) }\end{array}$ & 60,336 & NA & NA & 7.9 & 75,816 & 58,303 & 47,661 \\
\hline $\begin{array}{l}\text { Pegylated IFN- } \beta 1 \text { a; } \text { Plegridy }^{\text {TM }} \\
\quad \text { (August 2014) }\end{array}$ & 62,036 & NA & NA & 10.6 & 81,731 & 62,851 & 46,591 \\
\hline $\begin{array}{l}\text { Alemtuzumab; Lemtrada }{ }^{\mathrm{TM}} * \\
\quad \text { November 2014) }\end{array}$ & 65,833 & NA & NA & 1.2 & 69,166 & 53,189 & 60,466 \\
\hline Glatiramer acetate; Glatopa $^{\text {TM }}$ (April 2015) & 63,193 & NA & NA & 0 & 63,193 & 48,595 & 32,552 \\
\hline Daclizumab; Zinbryta $^{\mathrm{TM} *}$ (May 2016) & 82,000 & NA & NA & NA & 86,838 & 66,778 & 61,251 \\
\hline OcrevusTM* (March 2017) & 65,000 & NA & NA & NA & 65,000 & 49,985 & 49,400 \\
\hline
\end{tabular}

Wholesale Acquisition Cost (WAC) data accessed through FirstDataBank. Big Four Pricing data accessed through (https://www1.va.gov/nac/Pharma/ List). IFN = interferon; $\mathrm{SC}=$ subcutaneous; $\mathrm{NA}=$ not available

*June 2017

${ }^{\dagger}$ Acquisition costs estimating using wholesale acquisition costs. Medicaid rebate estimated to be $23.1 \%$ of WAC

${ }^{\ddagger}$ Natalizumab withdrawn from market in February 2005; reintroduced in June 2006

a number of ways. First, the growing use of high deductible/ high-cost-share health plans can expose individuals to excessive out-of-pocket costs [12]. While copay cards and other patient-assistance programs can mitigate exorbitant out-ofpocket expenses for patients, they do nothing to reduce total healthcare payer expenditures [20,21]. Additionally, individuals who receive government-funded healthcare, such as Medicare, are prohibited from using these programs because of federal antikickback laws [21]. Second, rising DMT expenditures have resulted in increasing levels of restriction by insurance and pharmacy benefit management companies. DMT selection, which should involve shared decision-making that takes into account clinical evidence and patient preferences, is often driven by rigid policies that require "failure" of one or more preferred DMT before using a nonpreferred agent [13].

The impact of higher DMT costs or insurance company restrictions on clinical outcomes is uncertain. Several studies have examined the relationship between out-of-pocket expenses and DMT adherence using administrative medical and pharmacy claims data. Two studies have examined the impact of co-insurance level on DMT adherence in commercially insured individuals with MS [22, 23]. In a study of nearly 3500 patients with MS, those who had the highest cost-sharing level (i.e., DMT out-of-pocket expenditures as a proportion of total expenditures) were significantly less likely to initiate a DMT relative to those with lower cost-sharing levels [22]. A similar study further examined the relationship between out-of-pocket expenditures and DMT adherence by comparing patients with coinsurance to those with copayments [23]. This study found that DMT adherence was only adversely affected among those with coinsurance (i.e., out-of-pocket expense is a proportion of total expense), and not those with copayment-type pharmacy benefits. Specifically, patients with the highest monthly out-of-pocket spending (average of \$1162 per month) only filled their DMT $25 \%$ of the time, whereas those with the lowest out-of-pocket expenditures were $100 \%$ adherent.

Two other studies in Medicare populations show a consistent relationship between cost exposure and adherence [24, 25]. In one analysis of 4180 Medicare beneficiaries with 
Table 2 Medicare Part D utilization and spending on disease-modifying therapies 2011 to 2015

2011

Spending

(\$)

\section{Claims}

(n)
2015

\begin{tabular}{llll}
\hline Spending & $\begin{array}{l}\text { Claims } \\
(\$)\end{array}$ & $\begin{array}{l}\text { Patients } \\
(n)\end{array}$ & $\begin{array}{l}\text { Spending/ } \\
\text { patient }\end{array}$
\end{tabular}

(\$)

\begin{tabular}{|c|c|c|c|c|c|c|c|c|}
\hline IFN- $\beta 1 b ;$ Betaseron $^{\mathrm{TM}}$ & $155,981,338$ & 47,873 & 5830 & 26,755 & $241,573,749$ & 40,255 & 4859 & 49,717 \\
\hline IFN- $\beta 1$ a IM; Avonex ${ }^{\text {TM }}$ & $349,108,226$ & 106,302 & 12,314 & 28,351 & $348,107,873$ & 61,330 & 7490 & 46,476 \\
\hline $\begin{array}{l}\text { Glatiramer acetate; } \\
\text { Copaxone }^{\mathrm{TM}} *\end{array}$ & $707,777,690$ & 188,828 & 22,731 & 31,137 & $1,382,386,515$ & 237,976 & 27,621 & 50,048 \\
\hline IFN- $\beta 1$ a SC; Rebif ${ }^{\text {TM }}$ & $194,050,544$ & 63,470 & 7399 & 26,227 & $378,253,134$ & 64,671 & 7752 & 48,794 \\
\hline Natalizumab; Tysabri ${ }^{\mathrm{TM}}$ & $7,770,739$ & 2204 & 313 & 24,827 & $30,548,895$ & 5828 & 775 & 39,418 \\
\hline 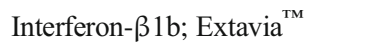 & $10,462,795$ & 4215 & 644 & 16,247 & $24,035,265$ & 5324 & 747 & 32,176 \\
\hline Fingolimod; Gilenya ${ }^{\mathrm{TM}}$ & $62,818,219$ & 14,402 & 2889 & 21,744 & $387,672,781$ & 57,470 & 7213 & 53,746 \\
\hline Teriflunomide; Aubagio ${ }^{\mathrm{TM}}$ & NA & NA & NA & NA & $292,038,853$ & 46,263 & 6910 & 42,263 \\
\hline Dimethyl fumerate; Tecfidera ${ }^{\mathrm{TM}}$ & NA & NA & NA & NA & $875,583,352$ & 136,426 & 18,798 & 46,579 \\
\hline Pegylated IFN- $\beta 1 \mathrm{a}$; Plegridy ${ }^{\text {TM }}$ & NA & NA & NA & NA & $8,050,336$ & 1310 & 318 & 25,316 \\
\hline Glatiramer acetate; Glatopa ${ }^{\text {тм }}$ & NA & NA & NA & NA & $29,181,271$ & 5854 & 1802 & 16,194 \\
\hline Alemtuzumab; Lemtrada ${ }^{\mathrm{TM}}$ & NA & NA & NA & NA & $4,349,084$ & 48 & 41 & 106,075 \\
\hline Total & $1,487,969,550$ & 427,294 & 52,120 & 28,549 & $4,001,781,108$ & 662,755 & 84,326 & 47,456 \\
\hline
\end{tabular}

Source data derived from Medicare Part D drug spending public use files (https://www.cms.gov/Research-Statistics-Data-and-Systems/Statistics-Trendsand-Reports/Information-on-Prescription-Drugs/2015MedicareData.html). Spending does not include negotiated rebates or discounts

IFN = interferon; $\mathrm{SC}=$ subcutaneous; $\mathrm{NA}=$ not available

*20- and 40-mg doses are not differentiated in data

MS, investigators compared DMT adherence and persistence (how long patients continued to take their DMT) between those with full copayments, those with partially subsidized copayments, and those with no copayment [24]. Similar to the commercial populations, copayment amount was significantly related to an erosion in DMT adherence over time. Additionally, patients with the highest copayment levels were significantly more likely to discontinue their therapy after entering the Medicare Part D coverage gap (i.e., the "donut hole"). Although another study that examined discontinuation of intramuscular IFN- $\beta 1 \mathrm{a}$ and glatiramer acetate after beneficiaries entered the coverage cap found no effect, this study had a small sample and large confidence intervals around its estimates of discontinuation [25].

The evidence of how restrictive drug policies or increasing out-of-pocket expenditures affect clinical outcomes is less clear. Several studies have been conducted to examine the relationship between DMT adherence and clinical and economic outcomes using pharmacy and medical claims data in commercially insured populations. ${ }^{26-29}$ These studies consistently demonstrate an inverse relationship between adherence, typically measured using the medication possession ratio, MS relapse, emergency department visits or hospitalizations, and medical (nonpharmacy) spending [26-28]. Another study found that patients with MS who switched or discontinued their DMT have significantly higher medical utilization and costs than those who remained on therapy [29], suggesting disruptions in therapy may have serious unintended consequences.

\section{Assessing the Economic Value of MS DMTs}

Although DMT costs are central to issues of access and affordability, they also need to be considered in the context of value. Value in healthcare, defined as the efficiency with which interventions deliver outcomes with respect to their costs [30], is typically measured using cost-effectiveness metrics. Available DMTs have been shown to reduce relapses, decrease disability, and improve health-related quality of life to varying degrees. The extent to which DMTs can prolong life, prevent premature disability, and improve individual quality of life impacts the ultimate value of these therapies. Cost-effectiveness analyses facilitate comparisons of different healthcare interventions by estimating costs and benefits over a defined period of time. It is important to note that while most DMT clinical trials are 1 to 2 years in length, MS disability develops over decades. Therefore, the long-term economic and health consequences of interventions are often projected over an extended time horizon using mathematical models.

In a comprehensive cost-effectiveness study, costs should include not only the direct costs of the intervention (e.g., DMT 
acquisition costs), but also all other associated downstream costs of the therapy and the condition. These can include costs associated with DMT harms or harms-prevention strategies (monitoring for side effects), costs attributed to relapses and hospitalizations, and costs accrued as a result of increased disability (home care, mobility devices). Additionally, experts recommend that indirect costs associated with lost productivity of the individual be factored in. This is particularly notable for individuals with MS, who often must leave the workforce as a result of disability. To facilitate comparisons across different conditions where outcomes are heterogeneous, costeffectiveness analyses commonly use the quality-adjusted life year (QALY) to capture both the quantity and quality of health expected from different interventions. QALYs are estimated by essentially discounting each additional year of life by a utility weight that approximates an individual's preference for being in a particular health state. Utilities can range from 0 to 1 , where 1 indicates a state of perfect health and 0 is death. For example, an intervention that, on average, prolonged life by 10 years with a utility of 0.65 would represented by 6.5 QALYs.

Following estimation of both costs and benefits, value is expressed using an incremental cost-effectiveness ratio (ICER). The ICER is calculated by dividing the incremental total costs of an intervention by the incremental total benefits. Inherent in the ICER concept is that applying no active treatment (e.g., supportive care) has both costs and health consequences. Therefore, it is important to emphasize that ICERs represent the incremental cost of generating an additional unit of benefit (e.g., cost per additional QALY). Although there is no uniformly agreed upon costeffectiveness threshold in the USA, interventions with ICERs < $\$ 150,000$ per QALY are broadly considered to be a good value. This threshold is based on assumptions espoused by economists and some authorities that a ICER threshold 3 times a nation's per capita income is reasonable, although the empiric basis for this not well established [31].

Numerous cost-effectiveness studies ofDMTs have been published over the years with considerable methodologic, analytic, and reporting heterogeneity $[32,33]$. Further, many of these studies examine the relative value individual therapies, often failing to capture the real-world intricacies such as imperfect adherence and DMT switching. In a recent systematic review of costeffectiveness studies of DMTs for MS, US-based studies consistently reported ICERs in excess of $\$ 150,000$ per QALY [32]. One study, which reported ICERs in excess of \$900,000/QALY for the IFNs and glatiramer, presented sensitivity analyses suggesting that a reduction in DMT prices to levels similar to that of the UK would bring ICERs in line with traditionally accepted US thresholds [34]. Choice of comparison is an important consideration in the design and interpretation of cost-effectiveness analyses. A standard active comparator is challenging to recommend uniformly because there is no consensus on the optimal therapeutic approach for MS. In a recent review of 37 economic studies,
Hawton et al. [33] noted that nearly three-quarters reported comparisons to supportive care. Because the incremental differences in efficacy between DMTs are not as pronounced relative to supportive care, studies examining the comparative value of DMTs typically result in much higher ICERs. A preferred approach would be to present cost and effectiveness estimates for all comparators, including supportive care, so all possible incremental assessments can be explored.

The Institute for Clinical and Economic Review, a USbased nonprofit organization that conducts clinical and economic health technology appraisals for treatments and diagnostics, recently completed a comprehensive systematic review and cost-effectiveness analysis of all DMTs for both relapsing-remitting MS and primary-progressive MS [35]. Their relapsing-remitting MS economic model simulated patient progression through 20 health states based on the Expanded Disability Status Scale. Disability progression for each DMT relative to supportive care (placebo) was informed by a network meta-analysis showing ocrelizumab, alemtuzmab, daclizumab, and natalizumb [relative risk (RR) 0.42-0.56] were the most effective, followed by dimethtyl fumerate, pegylated IFN- $\beta 1 \mathrm{a}, \mathrm{IFN}-\beta 1 \mathrm{~b}$, and fingolimod (RR $0.62-0.68$ ), and finally teriflunomide, glatiramer acetate, and the other IFNs (RR 0.72-0.86). Using WAC-based drug pricing net-estimated rebates, ICERs for all but one DMT (excluding ocrelizumab, which was without pricing data at the time of analysis) were well above accepted cost-effectiveness thresholds and ranged from $\$ 183,240$ for subcutaneous IFN- $\beta 1 \mathrm{~b}$ (Extavia $^{\text {TM })}$ to $\$ 355,115$ for subcutaneous IFN- $\beta 1$ a (Rebifrм, $22 \mu \mathrm{g}$ ). At \$38,277 per QALY, alemtuzumab was the only DMT to have an ICER $<\$ 150,000$ per QALY. While the primary analysis used a healthcare system perspective (only direct medical costs), a secondary analysis factoring in lost productivity (i.e., societal perspective) was quantitatively similar. The relatively low ICER for alemtuzumab is likely attributable to its unique dosing strategy ( 5 infusions in first year and 3 in the second year) and modeling assumptions where a diminishing proportion of patients $(<20 \%)$ require an annual dose after year 2 .

Relative to generic glatiramer acetate, ICERs were economically unattractive ( $>\$ 150,000$ per QALY) for all DMTs except IFN- $\beta 1$ b $250 \mu$ g (ExtaviaTM; $\$ 144,873$ per QALY) and alemtuzumab, which was more effective and less costly.

The ICER for ocrelizumab was not explicitly estimated because of a lack of pricing data at the time. However, using the $\$ 150,000$ per QALY threshold, the authors report ocrelizumab would require an annual net price of $\$ 58,608$ to be considered cost-effective. At its current WAC-based list price (\$65,000 annually), rebates of approximately $10 \%$ could achieve this net cost. For the remainder of DMTs, discounts from WAC of between $50 \%$ and $90 \%$ would be required in order to achieve accepted costs per QALY thresholds. For primary-progressive MS, where ocrelizumab is the only 
Food and Drug Administration-approved DMT, the annual cost required to achieve the $\$ 150,000$ per QALY thresholds was $\$ 14,367$.

\section{Potential Solutions}

Excessive pricing of prescription drugs has been under intense scrutiny by the public, media, and legislators. Recent public polls report that a large majority of Americans believe prescription drug affordability should be a top healthcare legislative priority [36]. A variety of policy proposals have been put forth intended to address dysfunction in the pharmaceutical market place. Efforts are underway in many states to pass legislation that would require pharmaceutical companies to publically disclose and justify high-priced drugs [37]. Included in most of these proposals are requirements that industry disclose product specific costs for research, manufacturing, and marketing under certain circumstances (e.g., excessive price increases or high initial acquisition costs). Proponents of these efforts argue that enhanced transparency of drug prices would allow decision-makers to counter the prevailing notion that high prices and profits are required to offset the costs and risk involved in bringing drugs to market. Additionally, increased public scrutiny could incentivize manufactures to moderate their pricing strategy. Indeed, faced with mounting public pressure, several manufacturers have made public pledges to keep drug price increases below a certain level [38, 39]. A separate transparency issue concerns the disconnect between list prices and net prices after rebates. As previously discussed, transactions in the pharmaceutical marketplace differ markedly by payer, are notoriously complex, and typically involve proprietary rebate and discount negotiations. Savings extracted from manufacturers through contracted rebates are not directly shared with patients. Costsharing by patients with high deductible or co-insurance ( $v S$ copayment) types of pharmacy benefit plans is based on list price and not net price, which is often substantially lower [40]. Consequently, patients are often faced with very large out-ofpocket costs. Over the last 5 years, large increases in list prices and growing rebates have driven an increase in the gap between list and net prices [41].

Another popular proposal concerns how Medicare purchases prescription drugs. Medicare is the largest single purchaser or prescription drugs in the USA, yet its establishing legislation prohibits the government from directly negotiating drug costs with manufacturers. Instead, the program relies on imbedded incentives for contracted Part D plans that negotiate individually with manufacturers and compete for beneficiaries. There is overwhelming public support and among many professional organizations, including the American Academy of Neurology, that Medicare should be permitted to use its purchasing power to leverage greater savings for patients and the government, similar to how it sets prices for other services [14, 42-44]. Because Medicare is also constrained in its ability to implement coverage restrictions, the ultimate effect of these potential negotiations on expenditures is not clear [45].

Finally, generic drugs provide significant economic relief in most therapeutic spaces. With the exception of the orally available agents, most DMTs are considered biologics and therefore generic manufacturers cannot bring competitors through traditional channels. In April of 2015, Sandoz received approval to market a generic version of glatiramer acetate (Glatopa ${ }^{\mathrm{TM}}$ ), making it the first generically available DMT [46]. Glatopa was approved through the traditional Abbreviated New Drug Application pathway and therefore is considered clinically substitutable with Copaxone $20 \mathrm{mg}$ $\left(\right.$ Teva $\left.^{\mathrm{TM}}\right)$. While Glatopa is the only product currently available, generic competitors of the 40-mg version of glatiramer acetate should appear in the near future [47]. Novartis will lose patent protection and marketing exclusivity for fingolimod, setting the stage for more generic competition in 2019 [48].

In the absence of systematic changes to the current pharmaceutical market, Kister and Corboy [49] have suggested several clinical approaches aimed at reducing the burden of the high cost of MS DMTs. First, they advocate research that supports alternative DMT dosing schedules. Specifically, pharmacologic mechanism of action and some preliminary clinical data support less frequent administration of fingolimod, glatiramer acetate $(20 \mathrm{mg})$, and natalizumab. Additionally, they note evidence supporting the off-label use of rituximab, which is substantially less expensive than available Food and Drug Administration-approved DMTs. Evidence from randomized trials and observational studies suggest that infusions of 1 to $2 \mathrm{~g}$ annually (WAC $\$ 16,704$ per $1000 \mathrm{mg}$ ) are effective [50-52]. Finally, leflunomide, which is available as a lower-cost generic (WAC $\$ 150$ for $30 \times 20$-mg tablets), is almost completely converted to teriflunomide in vivo [53], and may be a reasonable option for some individuals, although there are no clinical data to support this practice.

\section{Conclusions}

In summary, prescription drugs, and specifically DMTs, are the single largest medical expenditure for individuals with MS. Over the last decade, the acquisition costs for DMTs have risen at annual rates substantially above medical inflation and now exceed $\$ 70,000$ for many agents. In addition to stress on the healthcare system, the rapid rise in DMT costs also has negative effects on patient care and access to DMTs. Costeffectiveness analyses suggest most DMTs are excessively priced given established value benchmarks. While the reasons for high and escalating drug costs are multifactorial, many point to fundamental dysfunction in the pharmaceutical 
marketplace. As such, proposals to confront the high cost of prescription drugs have included a diversity of strategies that, applied in isolation, will likely not resolve this issue. Although the current presidential administration has publically telegraphed awareness and concern about the high cost of prescription drugs, specific policy solutions have yet to be advanced at the federal level.

Required Author Forms Disclosure forms provided by the authors are available with the online version of this article.

\section{References}

1. Noseworthy JH, Lucchinetti C, Rodriguez M, Weinshenker BG. Multiple sclerosis. N Engl J Med 2000;343(13):938-952.

2. Dilokthornsakul P, Valuck RJ, Nair KV, Corboy JR, Allen RR, Campbell JD. Multiple sclerosis prevalence in the United States commercially insured population. Neurology 2016;86(11):1014-1021.

3. Owens GM. Economic burden of multiple sclerosis and the role of managed sare organizations in multiple sclerosis management. $A m$ J Manag Care 2016;22(6 Suppl.):s151-s158.

4. O'Brien JA, Ward AJ, Patrick AR, Caro J. Cost of managing an episode of relapse in multiple sclerosis in the United States. BMC Health Serv Res 2003;3(1):17.

5. Koch-Henriksen N, Sorensen PS. The changing demographic pattern of multiple sclerosis epidemiology. Lancet Neurol 2010;9(5):520-532.

6. Tullman MJ. Overview of the epidemiology, diagnosis, and disease progression associated with multiple sclerosis. Am J Manag Care 2013;19(2 Suppl.):S15-S20.

7. Iezzoni LI, Ngo L. Health, disability, and life insurance experiences of working-age persons with multiple sclerosis. Mult Scler 2007;13(4):534-546.

8. Ivanova JI, Birnbaum HG, Samuels S, Davis M, Phillips AL, Meletiche D. The cost of disability and medically related absenteeism among employees with multiple sclerosis in the US. Pharmacoeconomics 2009;27(8):681-691.

9. Adelman G, Rane SG, Villa KF. The cost burden of multiple sclerosis in the United States: a systematic review of the literature. $J$ Med Econ 2013;16(5):639-647.

10. Hartung DM, Bourdette DN, Ahmed SM, Whitham RH. The cost of multiple sclerosis drugs in the US and the pharmaceutical industry: too big to fail? Neurology 2015;84(21):2185-2192.

11. Bin Sawad A, Seoane-Vazquez E, Rodriguez-Monguio R, Turkistani F. Price analysis of multiple sclerosis diseasemodifying therapies marketed in the United States. Curr Med Res Opin 2016;32(11):1783-1788.

12. Esper GJ, Hartung D, Avitzur O. The patient protection and affordable care act and chronic neurological illnesses: benefits and challenges. JAMA Neurol 2015;72(7):739-740.

13. Bourdette DN, Hartung DM, Whitham RH. Practices of US health insurance companies concerning MS therapies interfere with shared decision-making and harm patients. Neurol Clin Pract 2016;6(2): 177-182.

14. Daniel H. Stemming the escalating cost of prescription drugs: a position paper of the american college of physicians. Ann Intern Med 2016 Mar 29

15. Tag T, Rubinstein E. AMCP Guide to Pharmaceutical Payment Methods, 2013 Update (Version 3.0). Academy of Managed Care Pharmacy Aug 2013. 1083-4087.
16. Dabora MC, Turaga N, Schulman KA. Financing and distribution of pharmaceuticals in the United States. JAMA 2017;381:21-22.

17. Medicaid Rebates for Brand-Name Drugs Exceeded Part D Rebates by a Substantial Margin. In: General OoI, ed2015.

18. Examination of Health Care Cost Trends and Cost Drivers. Office of the Attorney General Commonwealth of Massachusetts; October $7,2016$.

19. Skolarus LE, Burke JF, Callaghan BC, Becker A, Kerber KA. Medicare payments to the neurology workforce in 2012 . Neurology 2015;84(17):1796-1802.

20. Howard DH. Drug companies' patient-assistance programs - helping patients or profits? N Engl J Med 2014;371(2):97-99.

21. Ross JS, Kesselheim AS. Prescription-drug coupons - no such thing as a free lunch. N Engl J Med 2013;369(13):1188-1189.

22. Romley J, Goldman D, Eber M, Dastani H, Kim E, Raparla S. Costsharing and initiation of disease-modifying therapy for multiple sclerosis. Am J Manag Care 2012;18(8):460-464.

23. Dor A, Lage MJ, Tarrants ML, Castelli-Haley J. Cost sharing, benefit design, and adherence: the case of multiple sclerosis. $A d v$ Health Econ Health Serv Res 2010;22:175-193.

24. Banahan BF, Datar M, Mendonca CM, Bentley JP, Phillips AL, Stewart M. Effect of medicare part d coverage on adherence with disease modifying drug therapy for multiple sclerosis. Annual Meeting of the Academy of Managed Care Pharmacy; April 1820, 2012; San Francisco.

25. Tamariz L, Uribe CL, Luo J, et al. Persistence with biologic therapies in the Medicare coverage gap. Am J Manag Care 2011;17(11): 753-759.

26. Ivanova JI, Bergman RE, Birnbaum HG, Phillips AL, Stewart M, Meletiche DM. Impact of medication adherence to diseasemodifying drugs on severe relapse, and direct and indirect costs among employees with multiple sclerosis in the US. J Med Econ 2012;15(3):601-609.

27. Oleen-Burkey M, Cyhaniuk A, Swallow E. Retrospective US database analysis of persistence with glatiramer acetate vs. available disease-modifying therapies for multiple sclerosis: 2001-2010. BMC Neurol 2014;14:11.

28. Steinberg SC, Faris RJ, Chang CF, Chan A, Tankersley MA. Impact of adherence to interferons in the treatment of multiple sclerosis: a non-experimental, retrospective, cohort study. Clin Drug Investig 2010;30(2):89-100.

29. Reynolds MW, Stephen R, Seaman C, Rajagopalan K. Healthcare resource utilization following switch or discontinuation in multiple sclerosis patients on disease modifying drugs. $J$ Med Econ 2010;13(1):90-98.

30. Porter ME. What is value in health care? $N$ Engl $J$ Med. 2010;363(26):2477-2481.

31. Neumann PJ, Cohen JT, Weinstein MC. Updating cost-effectiveness - the curious resilience of the $\$ 50,000$-per-QALY threshold. $N$ Engl J Med 2014;371(9):796-797.

32. Yamamoto D, Campbell JD. Cost-effectiveness of multiple sclerosis disease-modifying therapies: a systematic review of the literature. Autoimmun Dis 2012;2012:784364.

33. Hawton A, Shearer J, Goodwin E, Green C. Squinting through layers of fog: assessing the cost effectiveness of treatments for multiple sclerosis. Appl Health Econ Health Policy 2013;11(4): 331-341.

34. Noyes K, Bajorska A, Chappel A, et al. Cost-effectiveness of disease-modifying therapy for multiple sclerosis: a populationbased study. Neurology 2011;77(4):355-363.

35. Disease-Modifying Therapies for Relapsing-Remitting and Primary-Progressive Multiple Sclerosis: Effectiveness and Value. Institute for Clinical and Economic Review; 2017.

36. Kirzinger A, Wu B, Brodie M. Kaiser Health Tracking Poll: Health Care Priorities for 2017. January 6, 2017. 
37. Sarpatwari A, Avorn J, Kesselheim AS. State initiatives to control medication costs - can transparency legislation help? N Engl J Med 2016;374(24):2301-2304.

38. Mukherjee S. This drug company just made a huge pledge on its prices. Fortune. May 9, 2017.

39. Johnson A. Drugmakers pledge restraint, but prices will still soar. Associated Press. Februrary 27, 2017.

40. Dusetzina SB, Conti RM, Yu NL, Bach PB. Association of Prescription Drug Price Rebates in Medicare Part D With Patient Out-of-Pocket and Federal Spending. JAMA Intern Med 2017;177: 1185-1188.

41. Medicines use and spending in the U.S: A Review of 2016 and Outlook to 2021. IMS Institute for Healthcare Informatics; 2017.

42. Singh R, Palosky C. Majorities of Democrats, Republicans and Independents Support Actions to Lower Drug Costs, Including Allowing Americans to Buy Drugs from Canada. The Henry J. Kaiser Family Foundation; 2017.

43. Drug Coverage \& Spending Reports From Council on Medical Service. AMA; 2015.

44. AAN Position Statement: Prescription Drug Prices.Minneapolis, $\mathrm{MN} ; 2017$.

45. Shih C, Schwartz J, Coukell A. How would government negotiation of medicare part d drug prices work? HealthAffairs Blog 2016.
46. Bourdette D, Hartung D. Equivalence of glatiramer acetate generics with branded glatiramer acetate in efficacy and cost for the treatment of multiple sclerosis. JAMA Neurol 2015;72(12):1411-1413.

47. Helfand C. Teva faces billions in lost sales as court tosses four longacting Copaxone patents. FiercePharma 2017.

48. Sagonowsky E. Novartis' Gilenya patent loss sets MS market up for battle with early generics. FiercePharma http://www.fiercepharma. com/pharma/novartis-loses-gilenya-patent-appeal-knocking-offyears-protection Publication date: Apr 13, 2017.

49. Kister I, Corboy JR. Reducing costs while enhancing quality of care in MS. Neurology 2016;87(15):1617-1622.

50. Alping P, Frisell T, Novakova L, et al. Rituximab versus fingolimod after natalizumab in multiple sclerosis patients. Ann Neurol 2016;79(6):950-958.

51. Hauser SL, Waubant E, Arnold DL, et al. B-cell depletion with rituximab in relapsing-remitting multiple sclerosis. $N$ Engl $\mathrm{J} \mathrm{Med}$. 2008;358(7):676-688.

52. Bar-Or A, Calabresi PA, Arnold D, et al. Rituximab in relapsingremitting multiple sclerosis: a 72-week, open-label, phase I trial. Ann Neurol 2008;63(3):395-400.

53. Claussen MC, Korn T. Immune mechanisms of new therapeutic strategies in MS: teriflunomide. Clin Immunol 2012;142(1):49-56. 